\title{
HOLE SUMMARIES
}





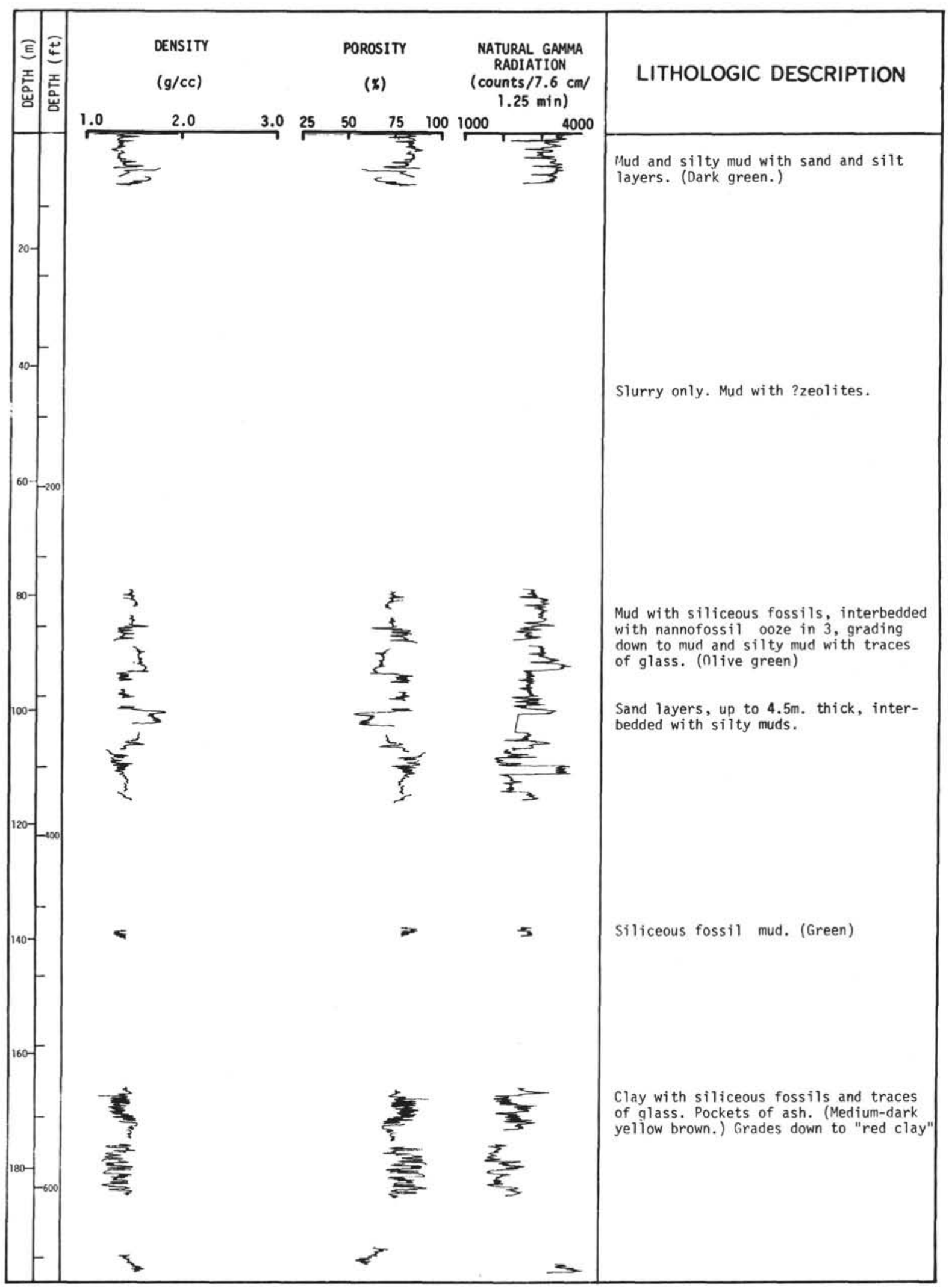

Figure 1. Summary of Physical Properties and Lithology of Hole 32. 


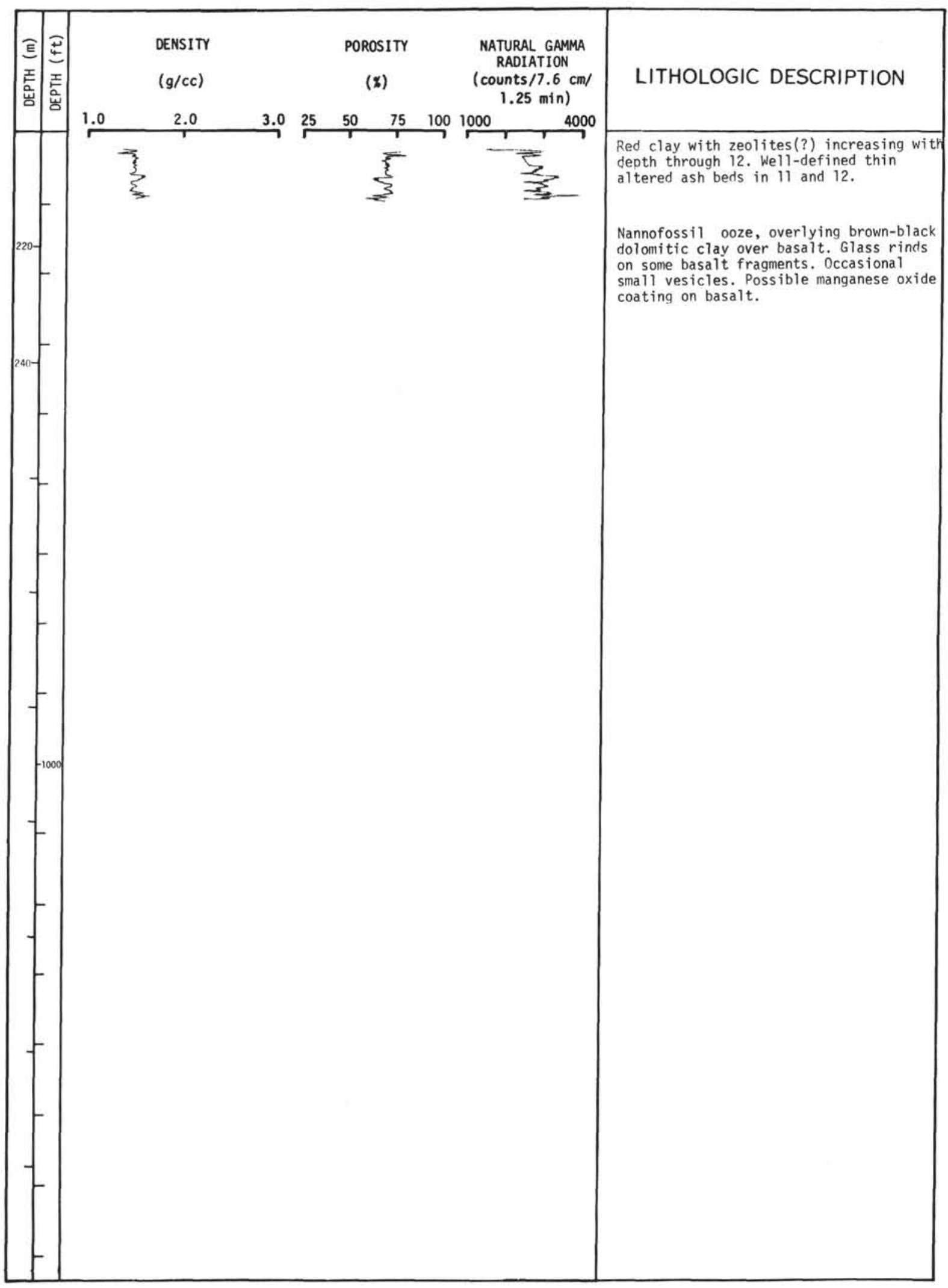

Figure 2. Summary of Physical Properties and Lithology of Hole 32. (Continued) 
NOT COMPLETED

Figure 3. Summary of Cores and Diagnostic Fossils from Hole 32. 


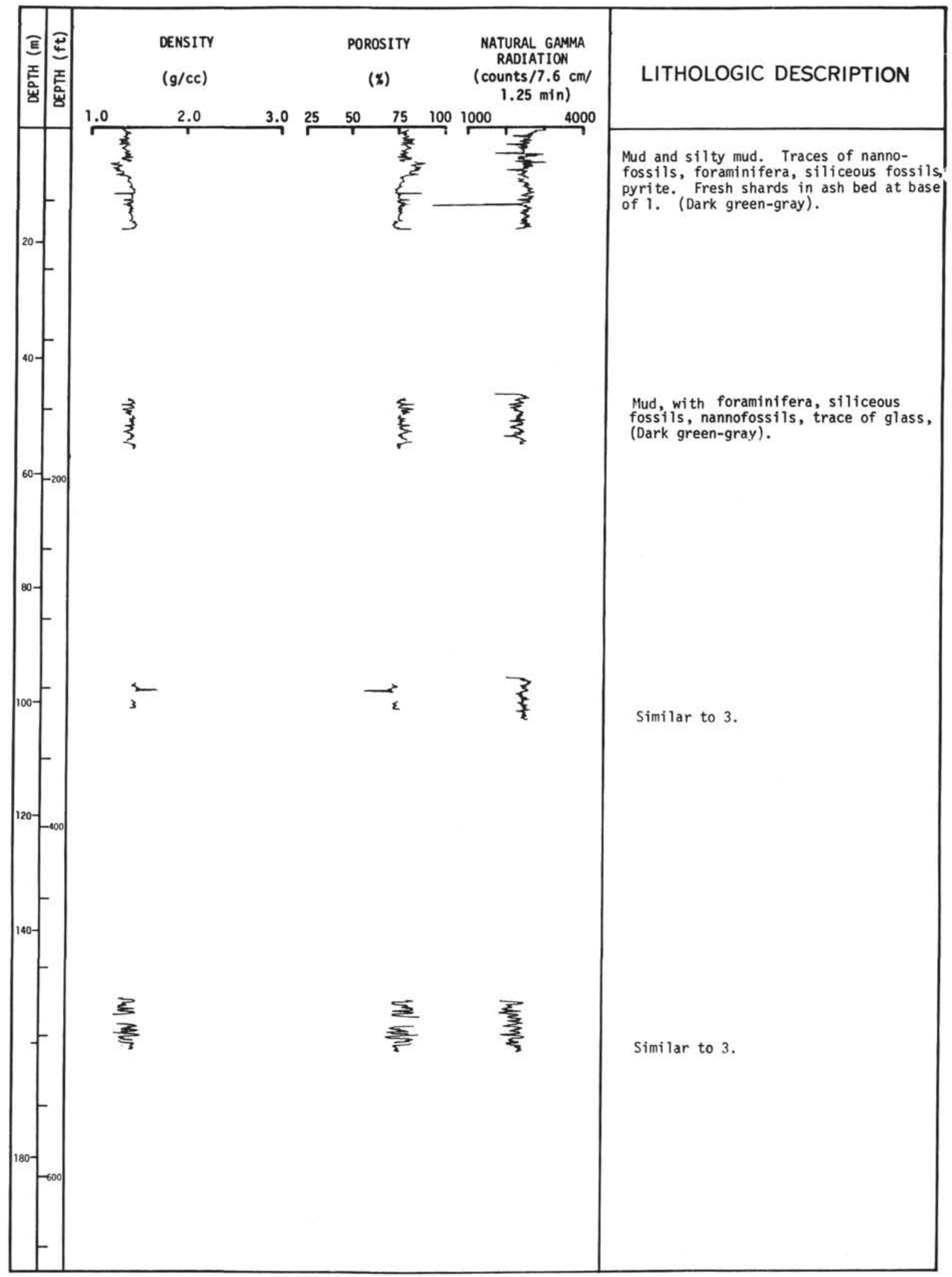

Figure 4. Summary of Physical Properties and Lithology of Hole 33. 


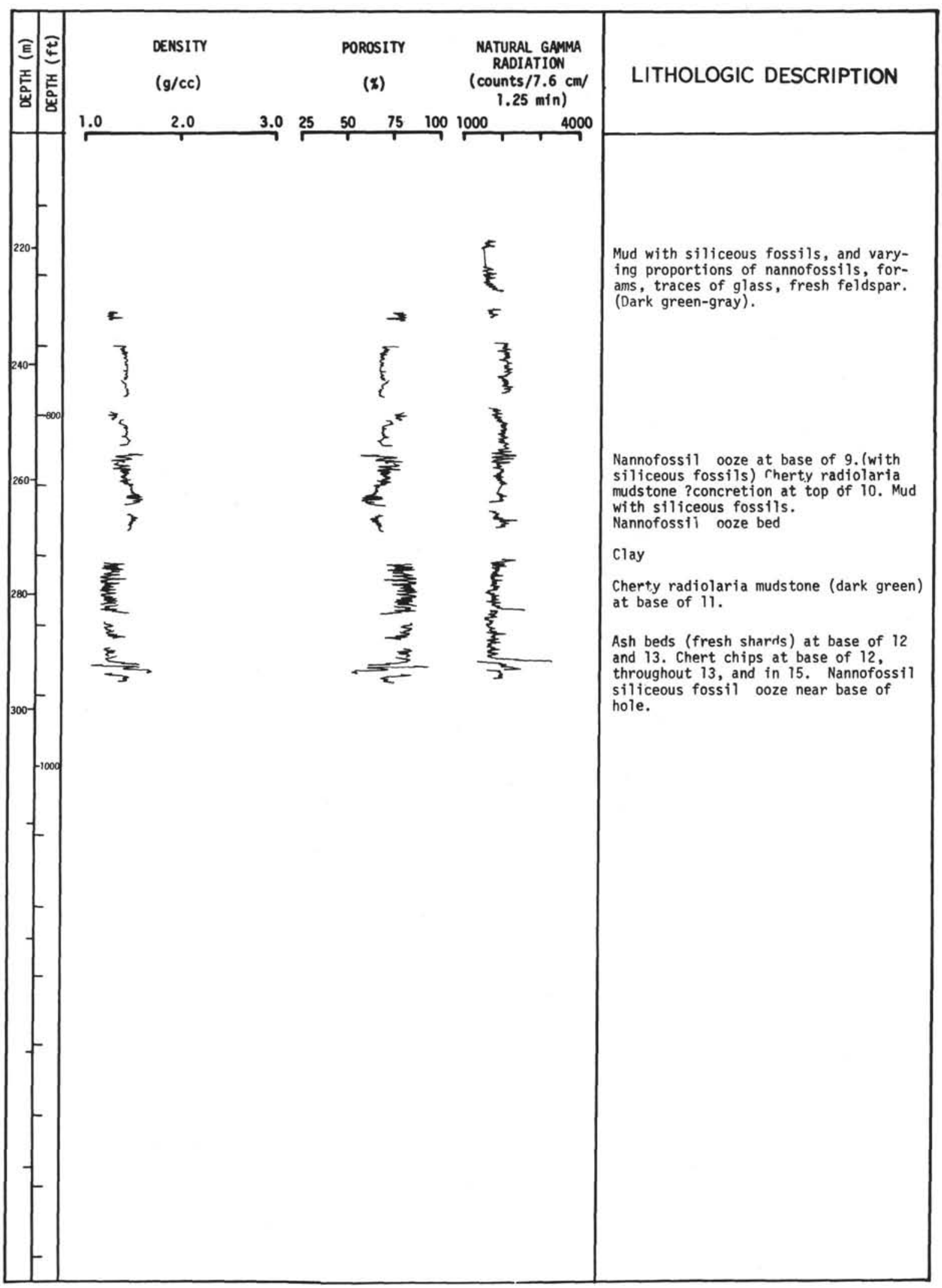

Figure 5. Summary of Physical Properties and Lithology of Hole 33 (continued). 
NOT COMPLETED

Figure 6. Summary of the Cores and Diagnostic Fossils from Hole 33. 


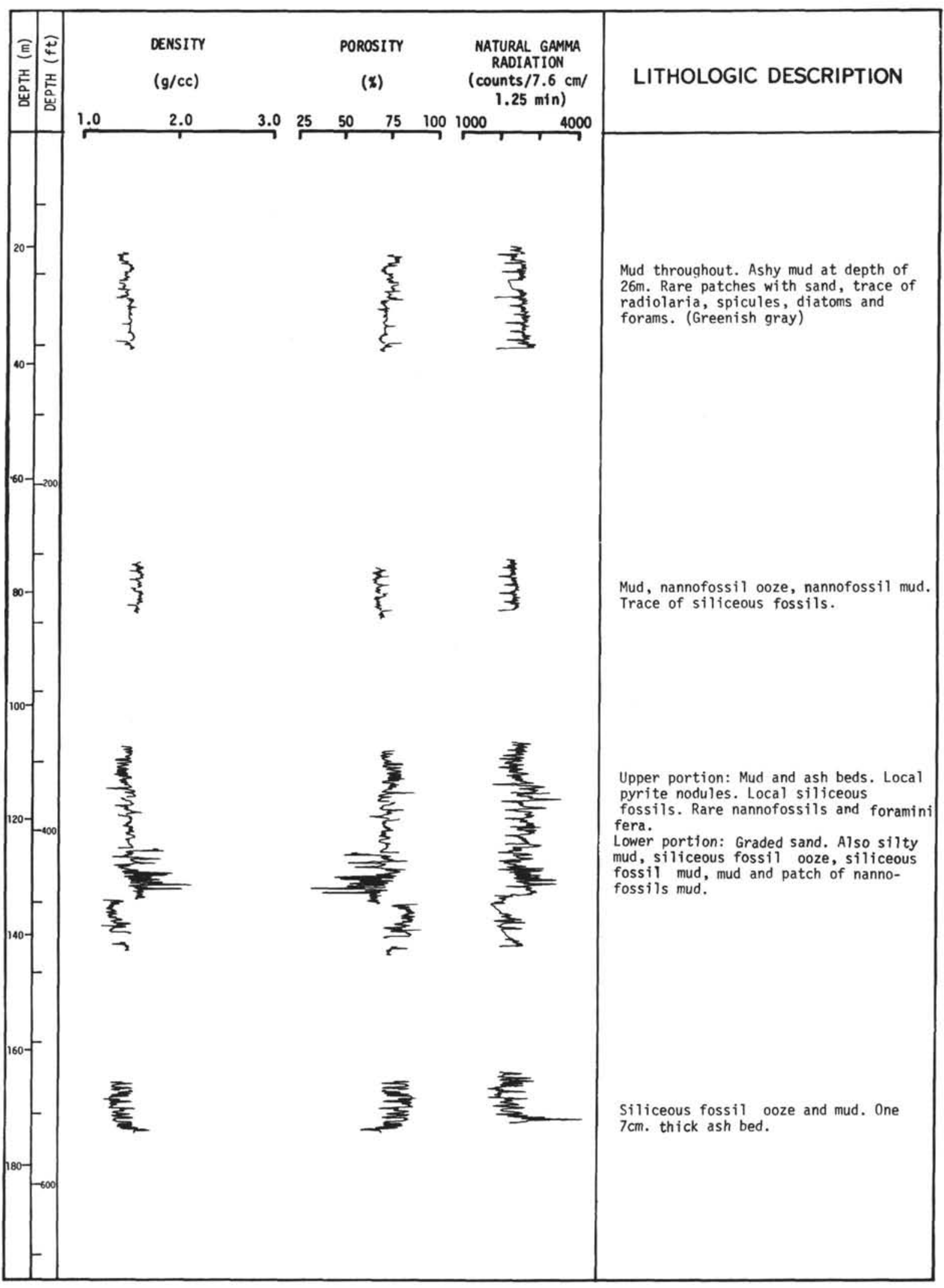

Figure 7. Summary of Physical Properties and Lithology of Hole 34. 


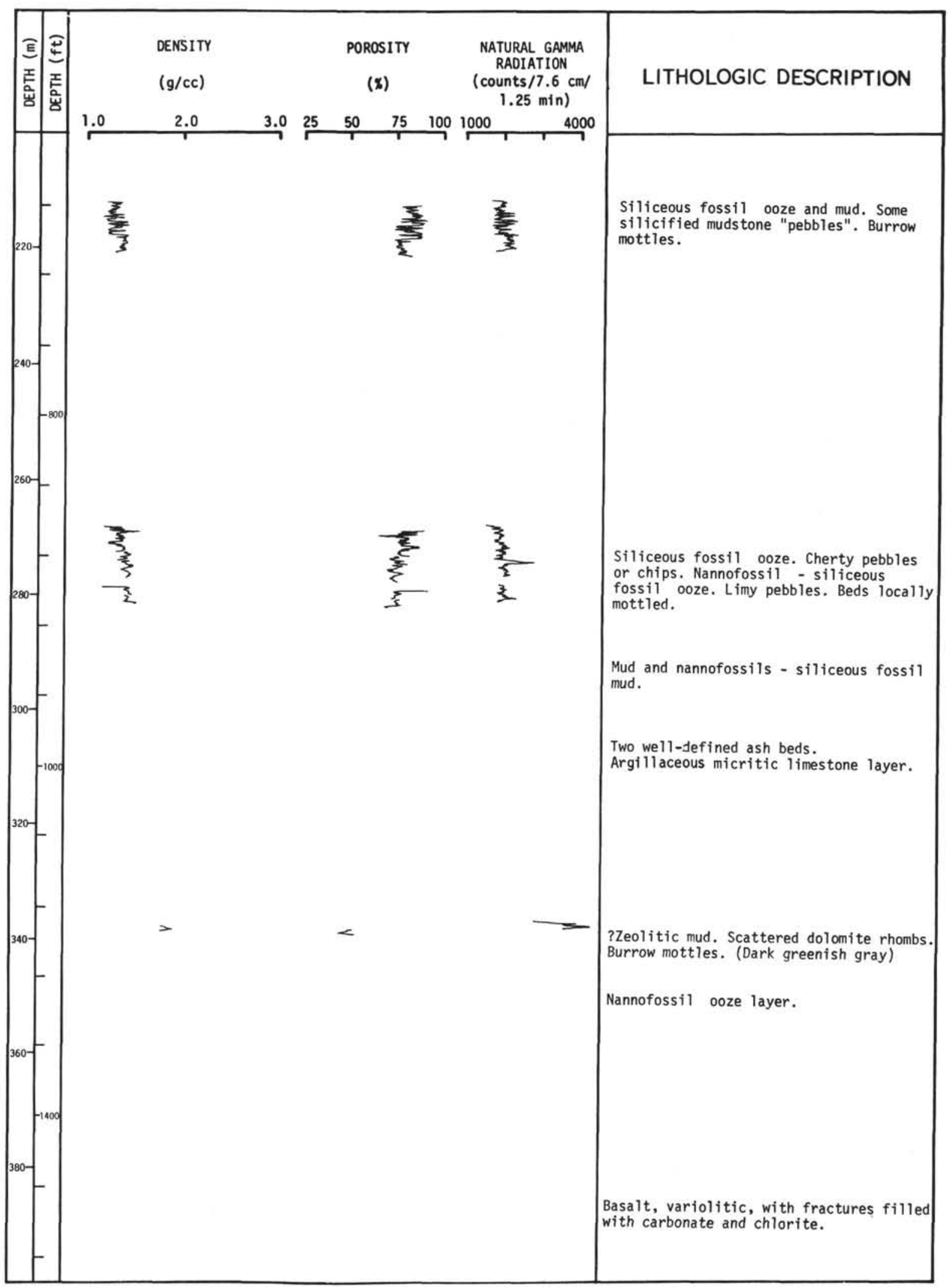

Figure 8. Summary of Physical Properties and Lithology of Hole 34 (continued). 
NOT COMPLETED

Figure 9. Summary of Cores and Diagnostic Fossils from Hole 34. 


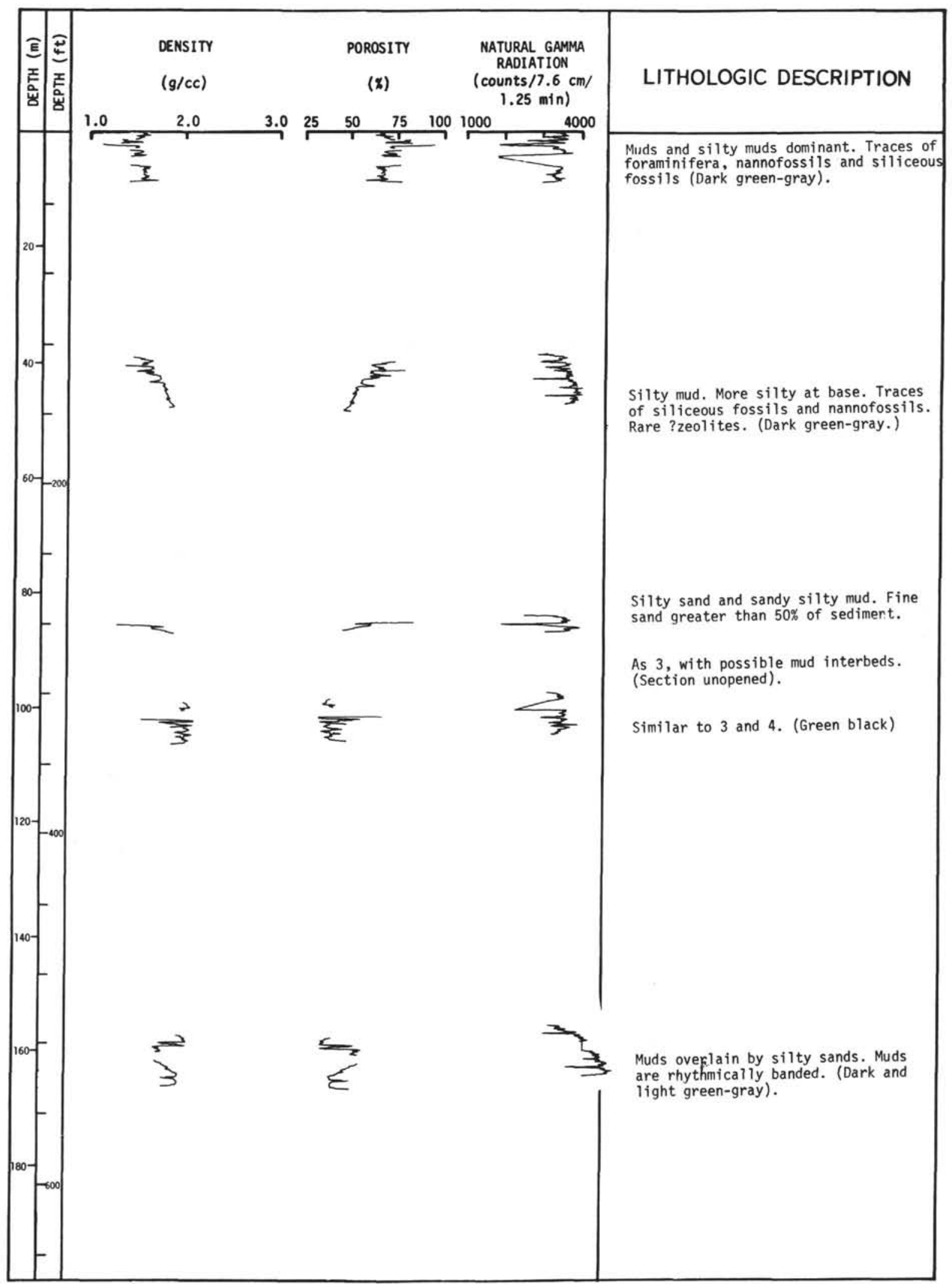

Figure 10. Summary of Physical Properties and Lithology of Hole 35. 


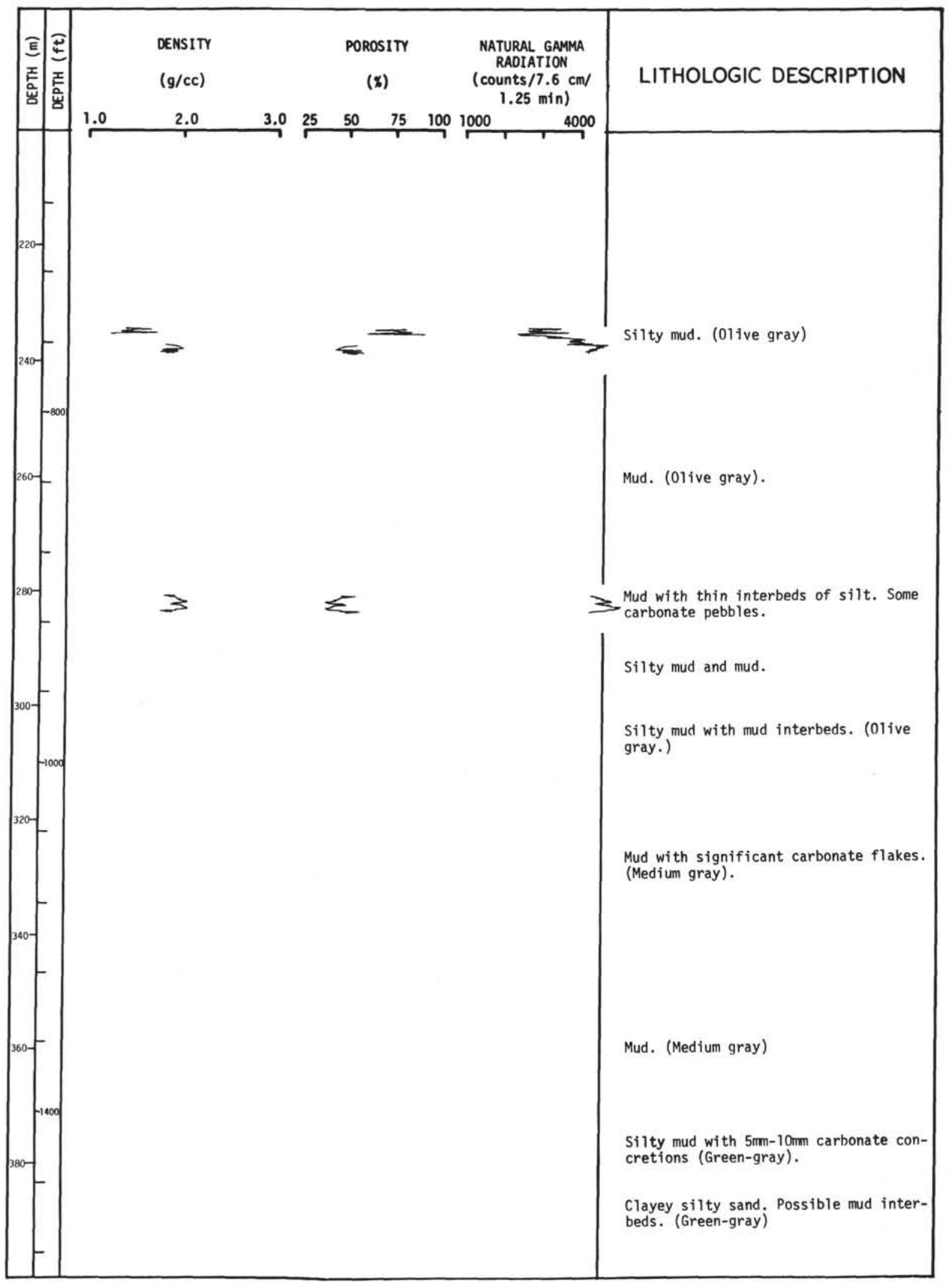

Figure 11. Summary of Physical Properties and Lithology of Hole 35 (continued). 


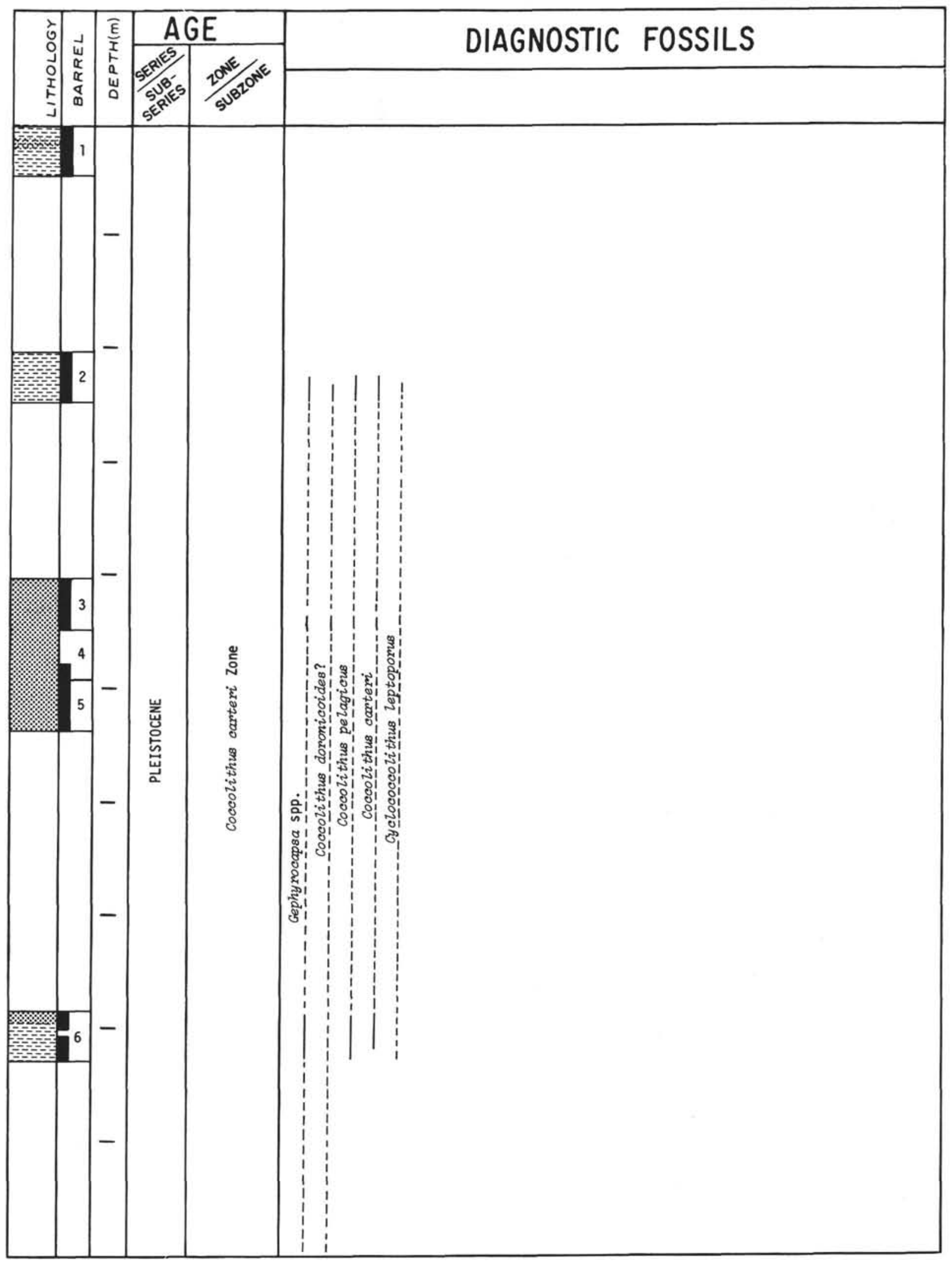

Figure 12. Summary of Cores and Diagnostic Fossils from Hole 35. 



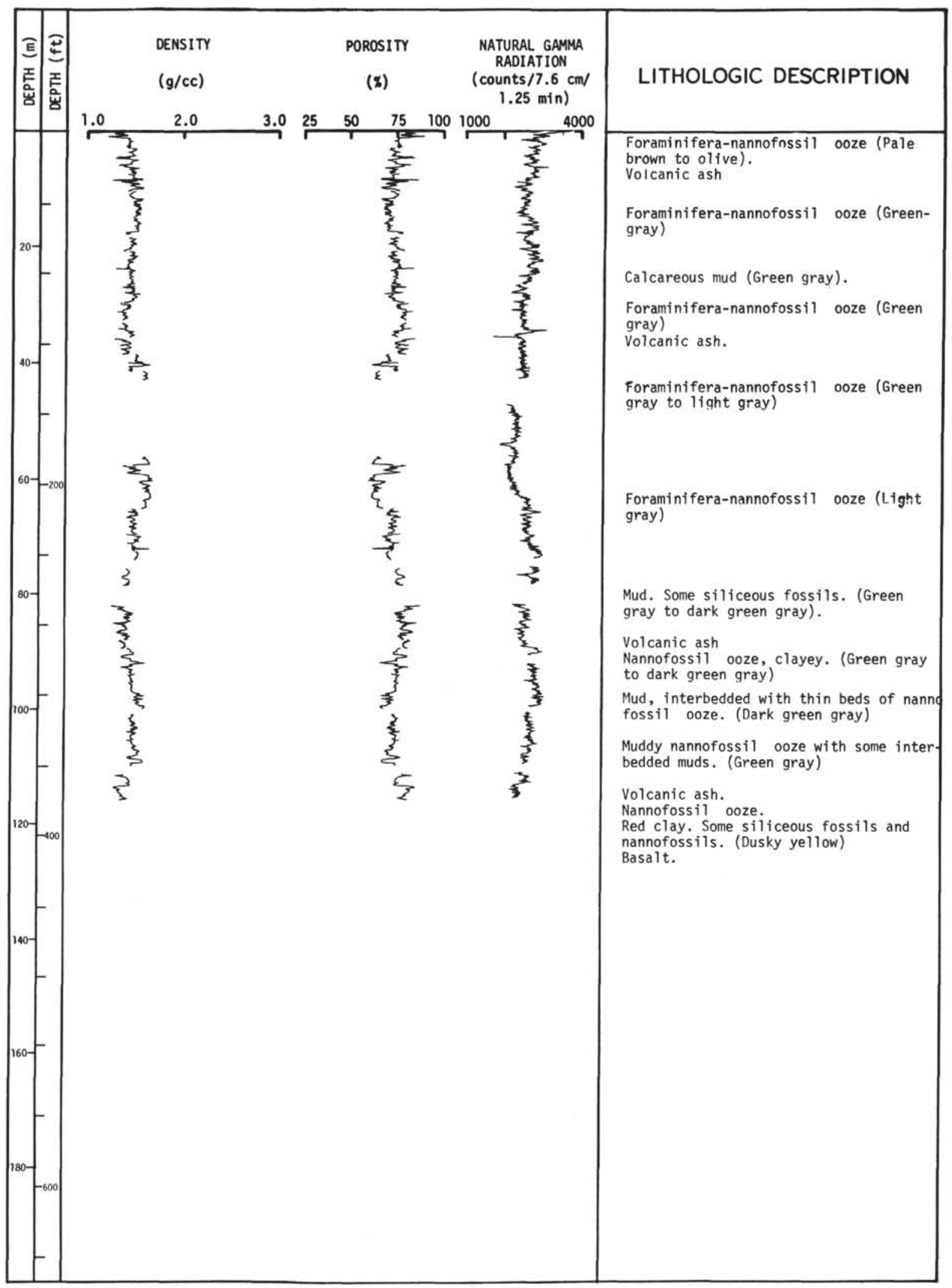

Figure 13. Summary of Physical Properties and Lithology of Hole 36. 


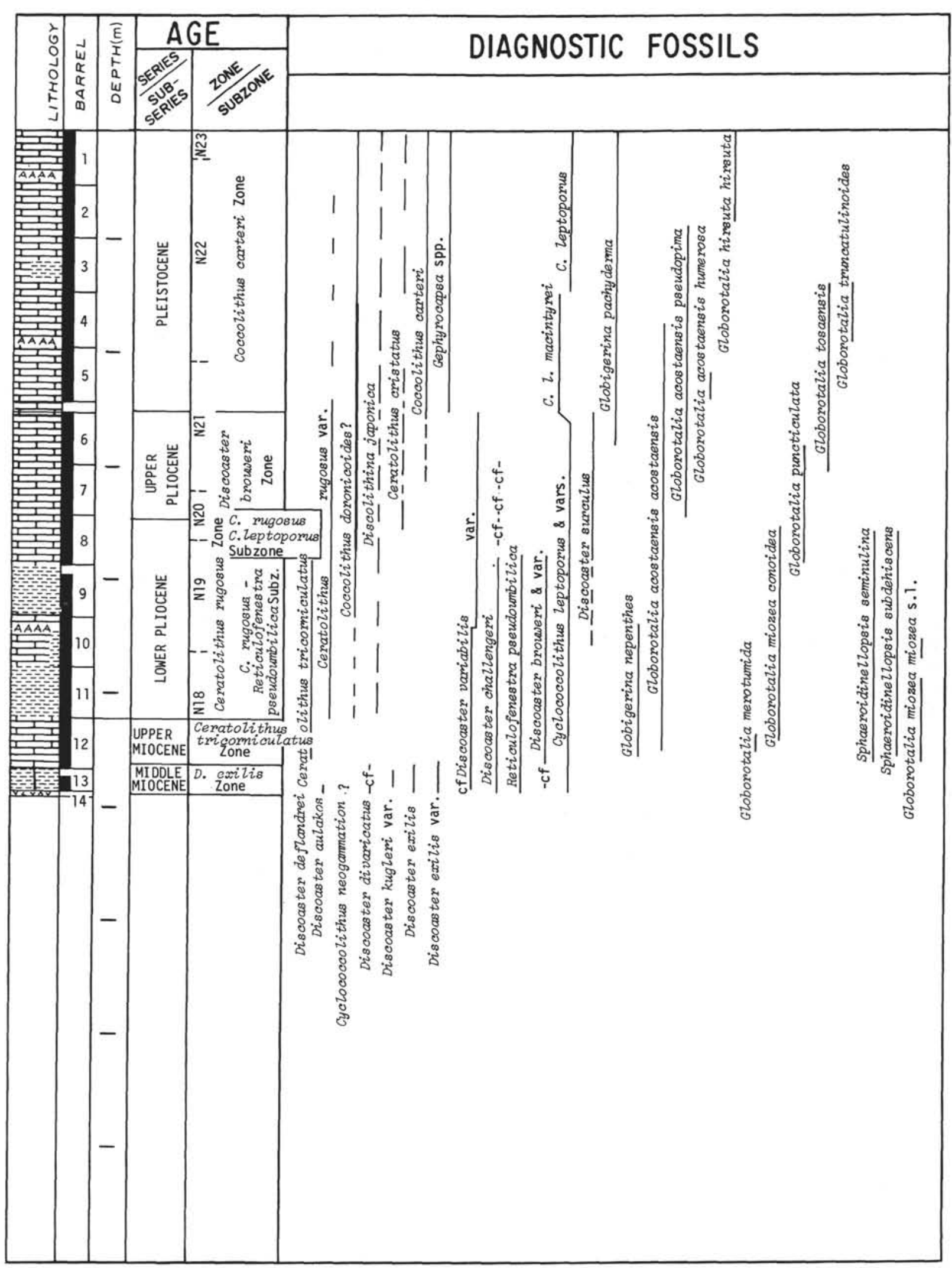

Figure 14. Summary of Cores and Diagnostic Fossils from Hole 36. 


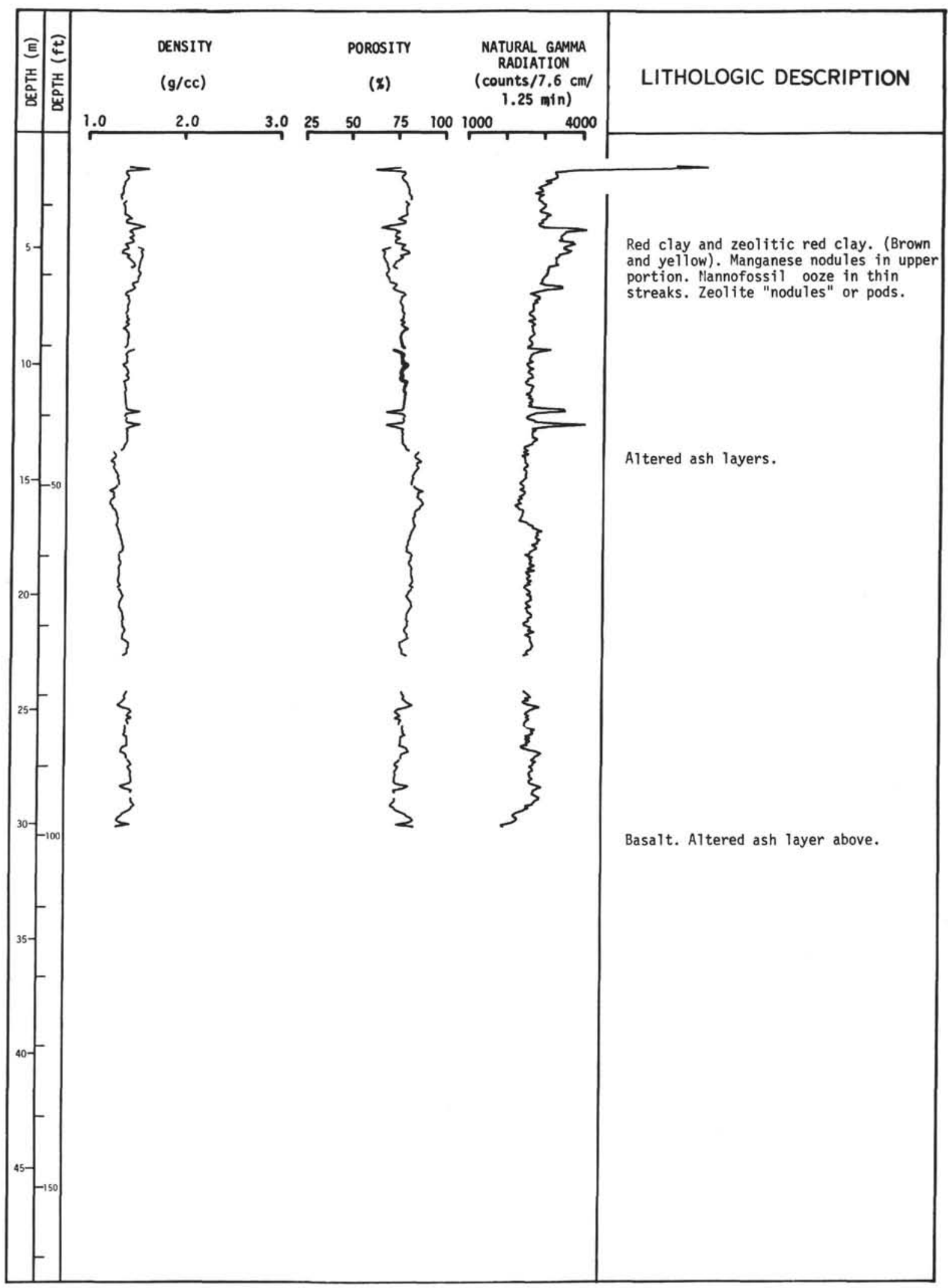

Figure 15. Summary of Physical Properties and Lithology of Hole 37. 


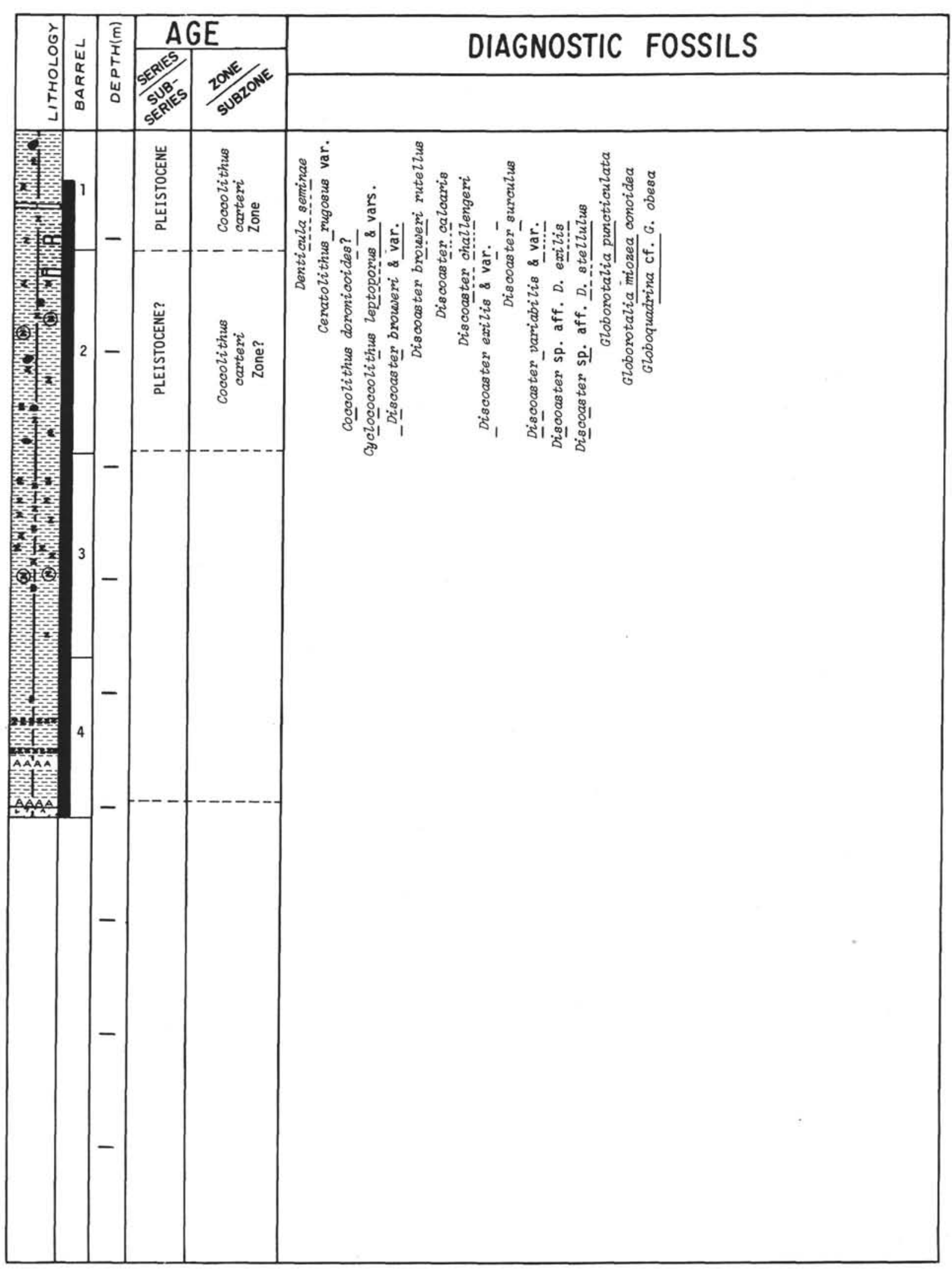

Figure 16. Summary of Cores and Diagnostic Fossils from Hole 37. 


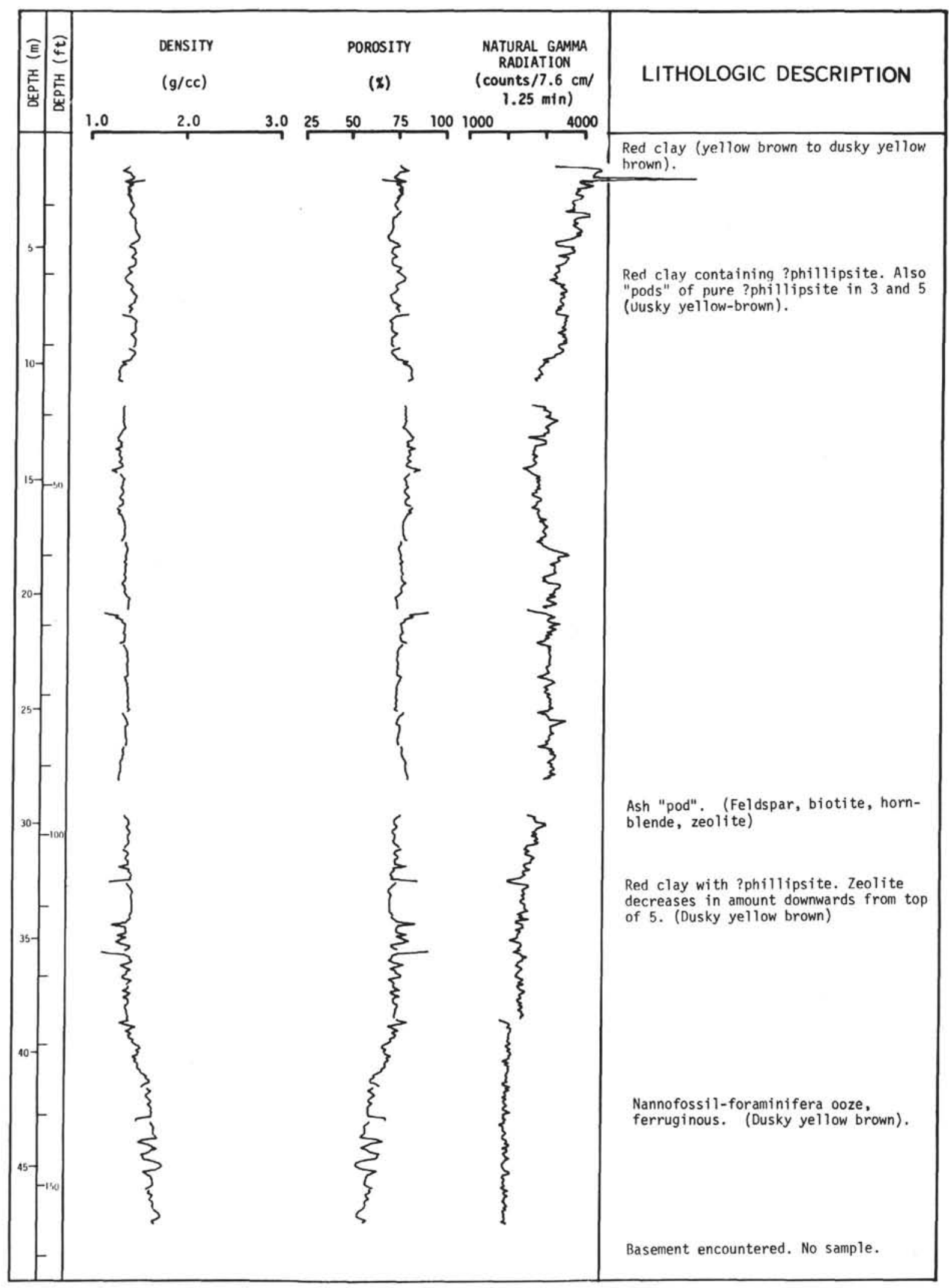

Figure 17. Summary of Physical Properties and Lithology of Hole 38. 


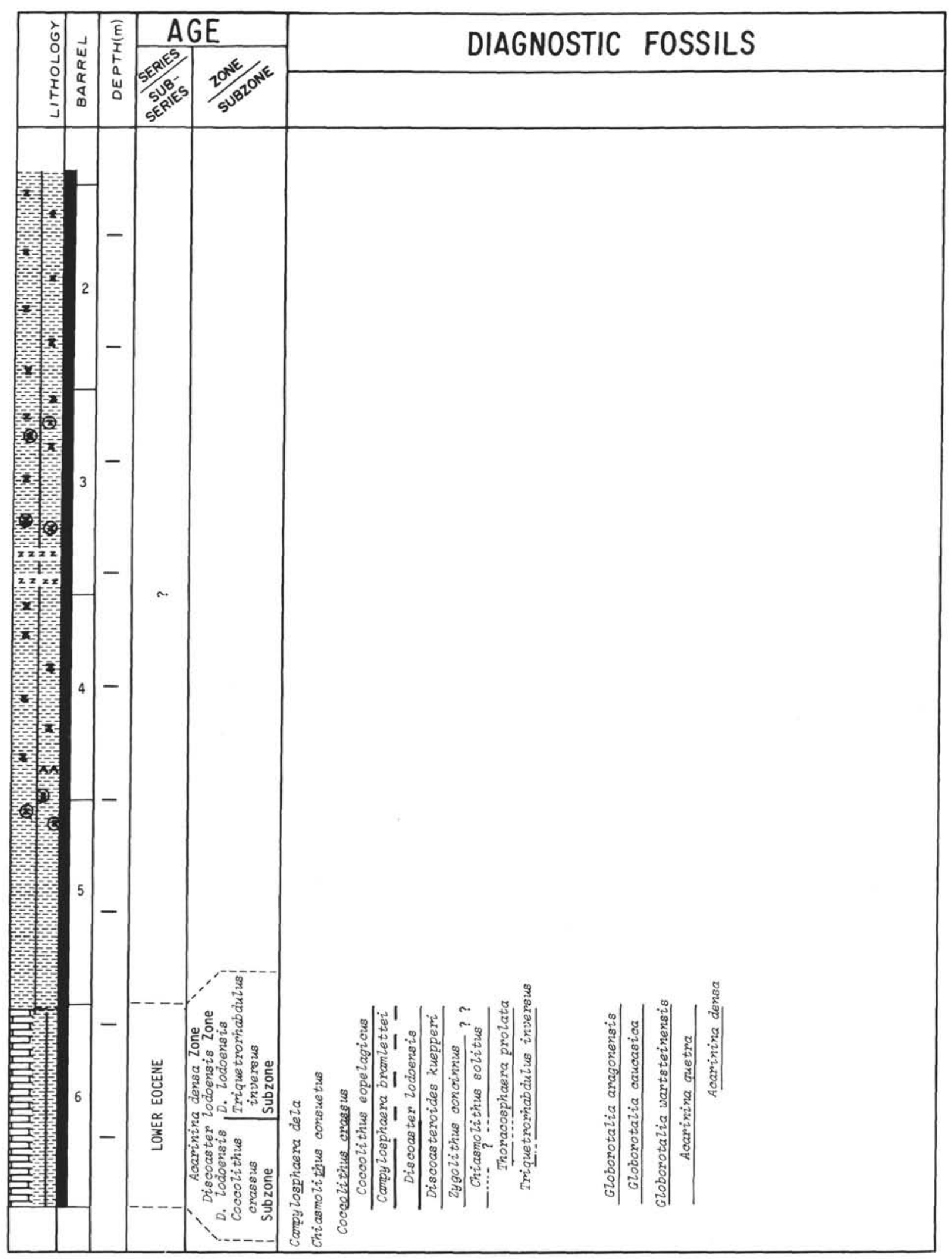

Figure 18. Summary of Cores and Diagnostic Fossils from Hole 38. 


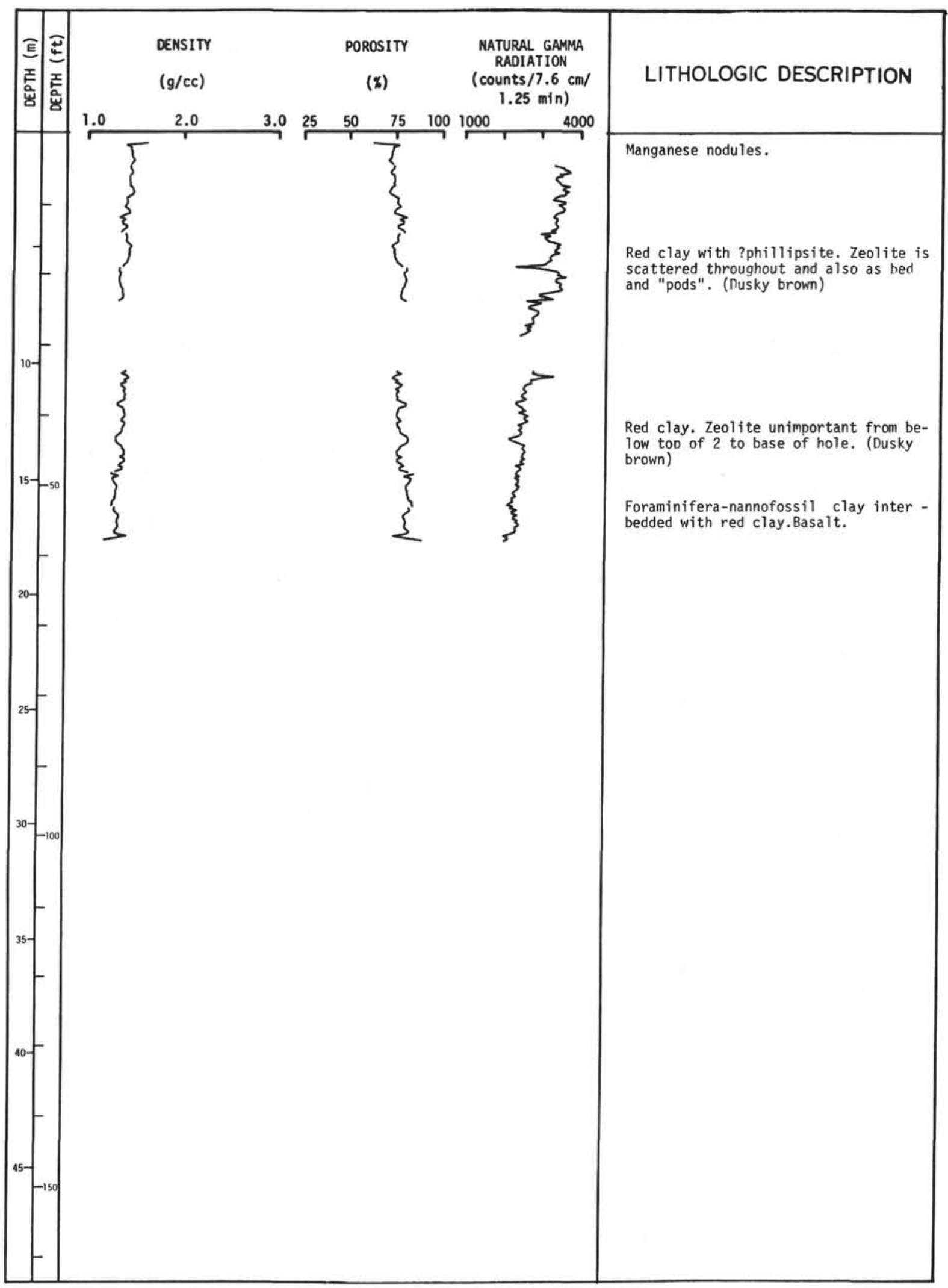

Figure 19. Summary of Physical Properties and Lithology of Hole 39. 


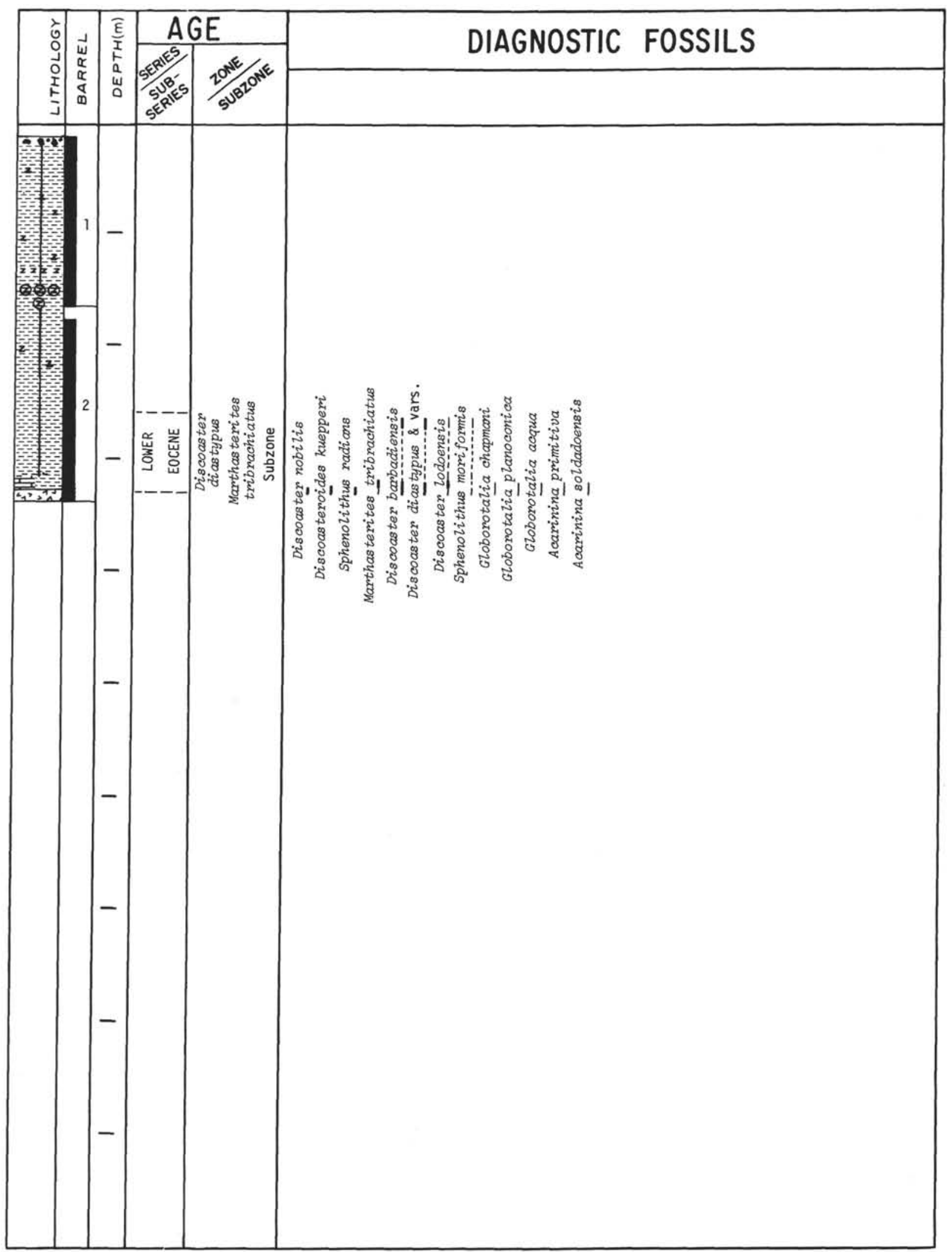

Figure 20. Summary of Cores and Diagnostic Fossils from Hole 39. 


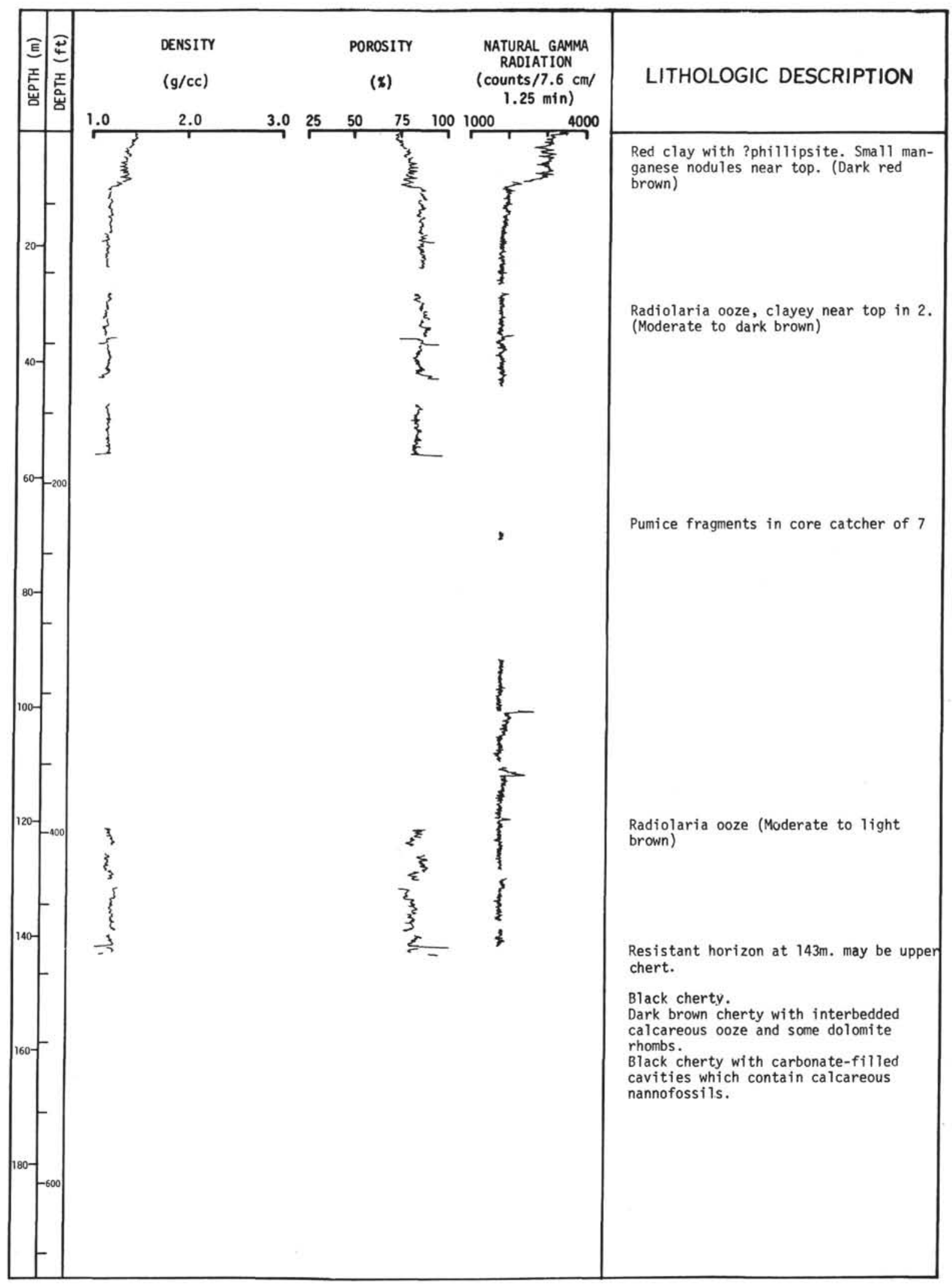

Figure 21. Summary of Physical Properties and Lithology of Hole 40. 


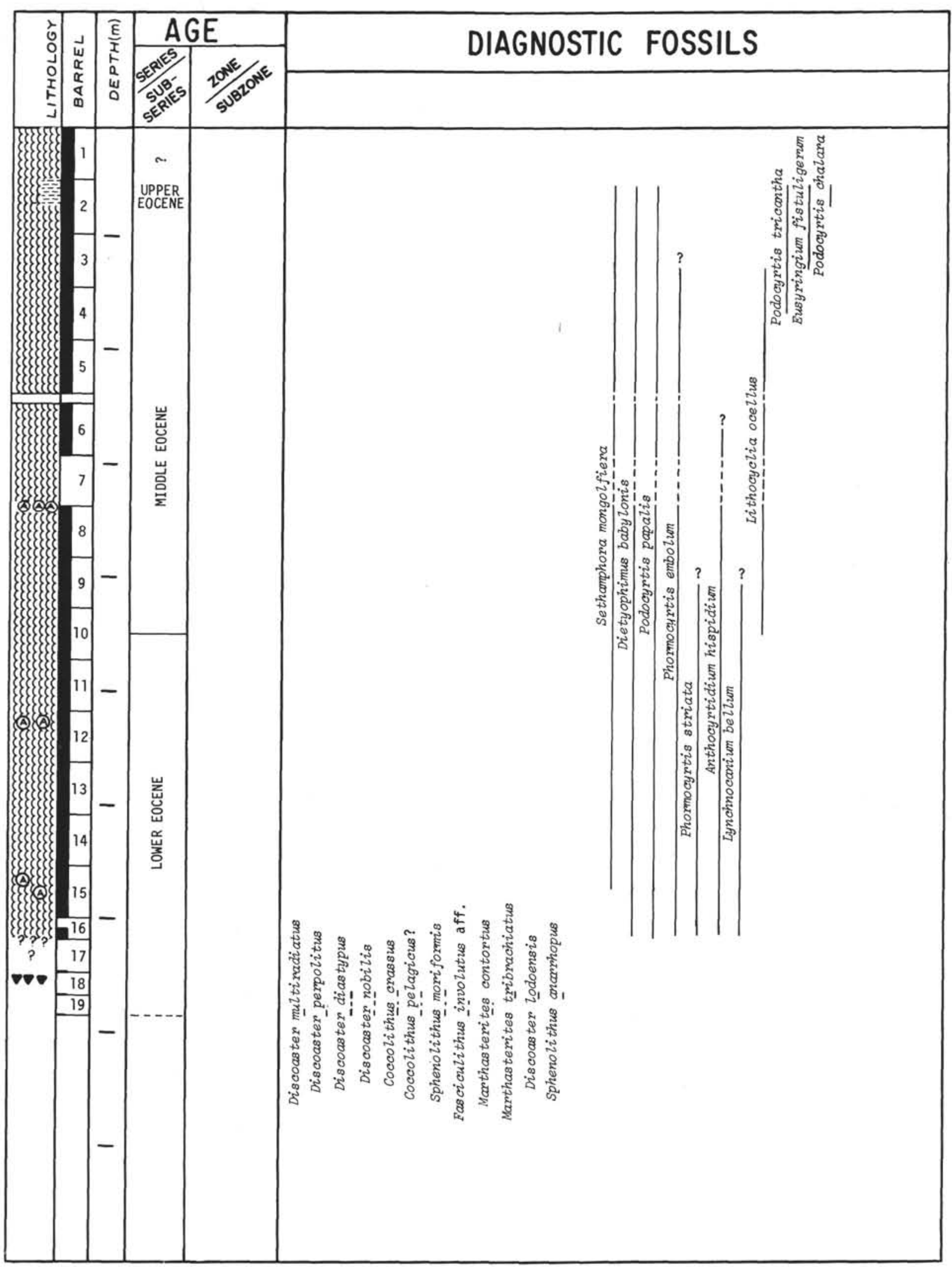

Figure 22. Summary of Cores and Diagnostic Fossils from Hole 40. 


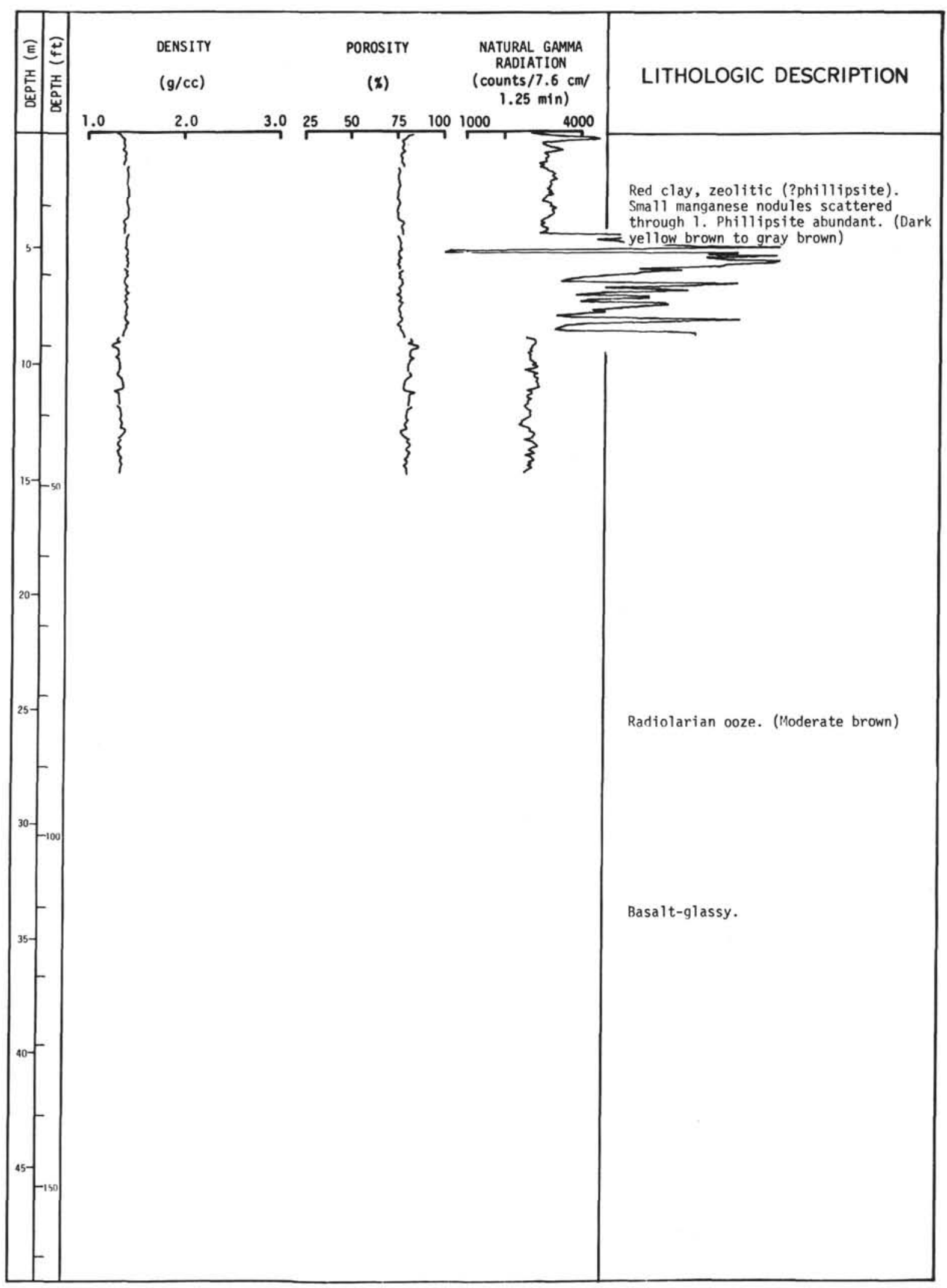

Figure 23. Summary of Physical Properties and Lithology of Hole 41. 


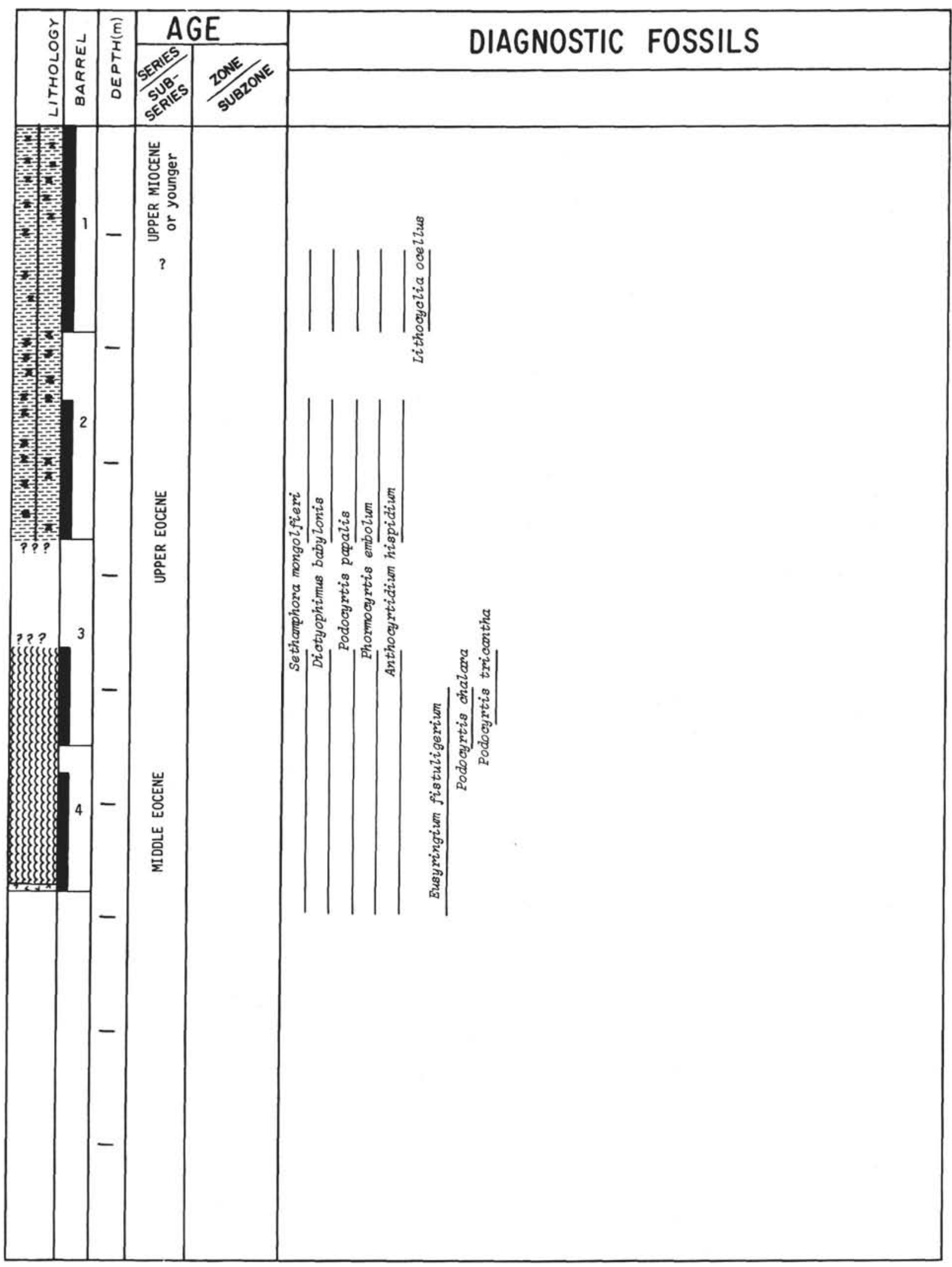

Figure 24. Summary of Cores and Diagnostic Fossils from Hole 41. 


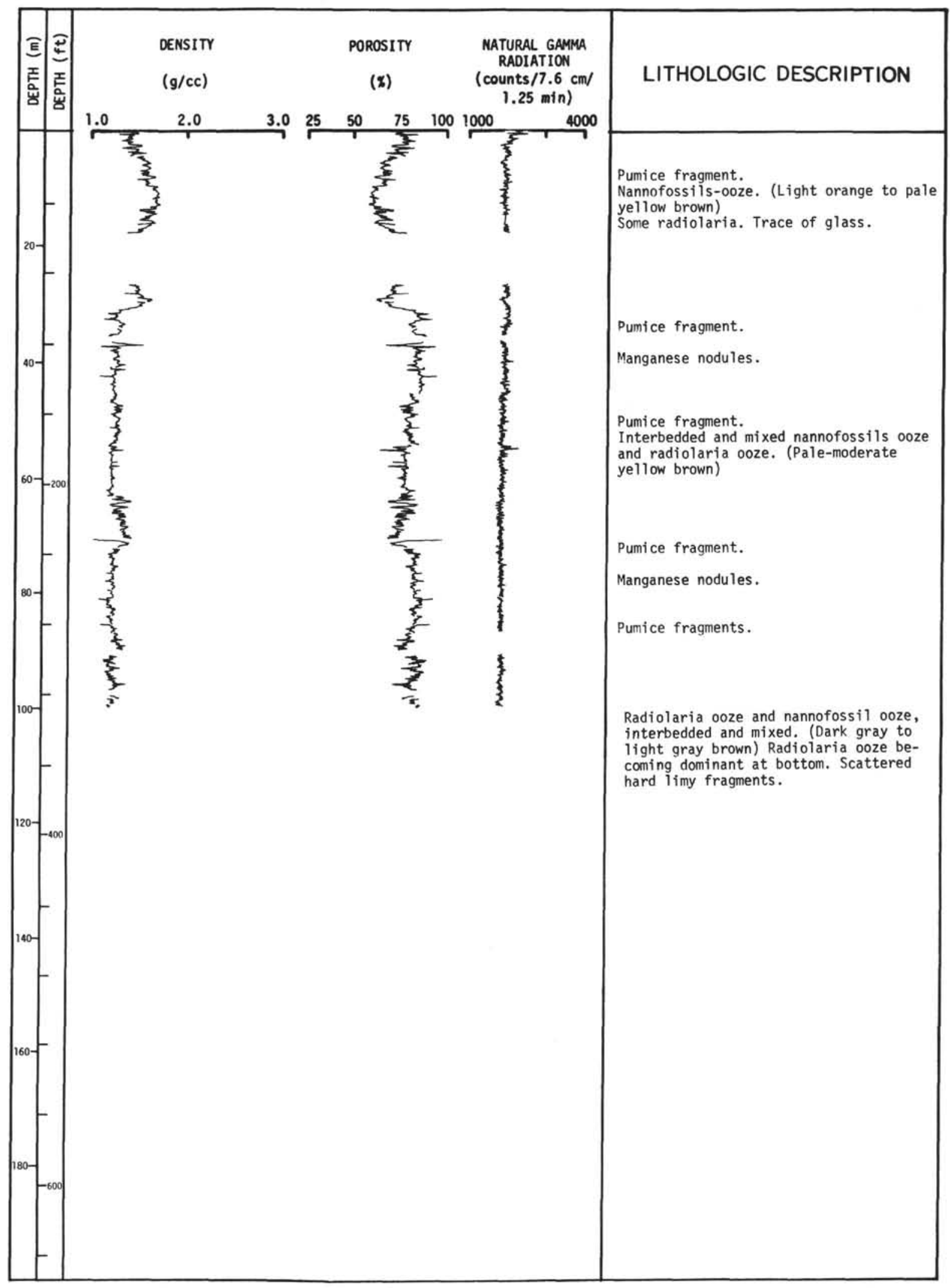

Figure 25. Summary of Physical Properties and Lithology of Holes 42.0 and 42.1 . 


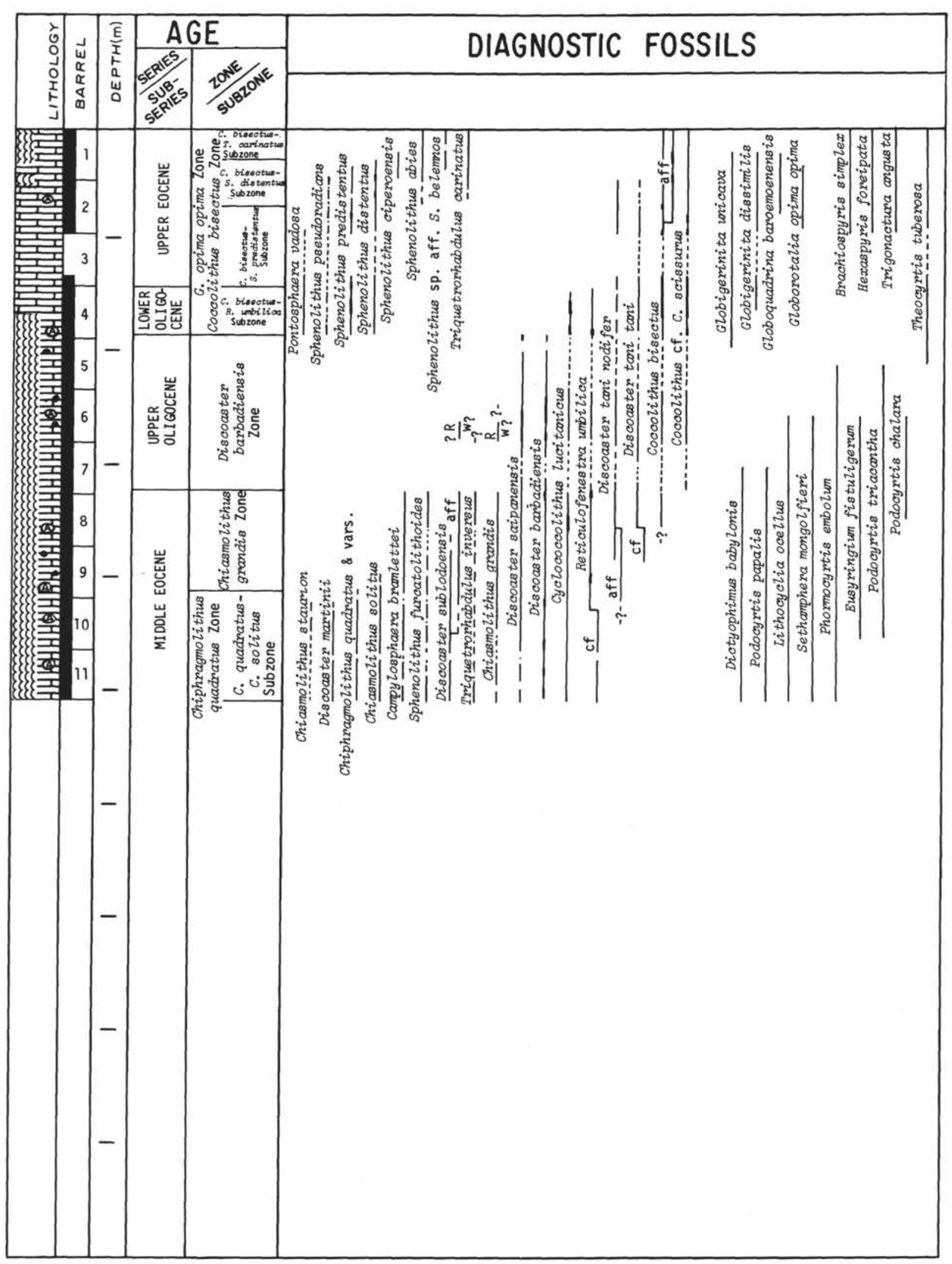

Figure 26. Summary of Cores and Diagnostic Fossils from Hole 42.0. 


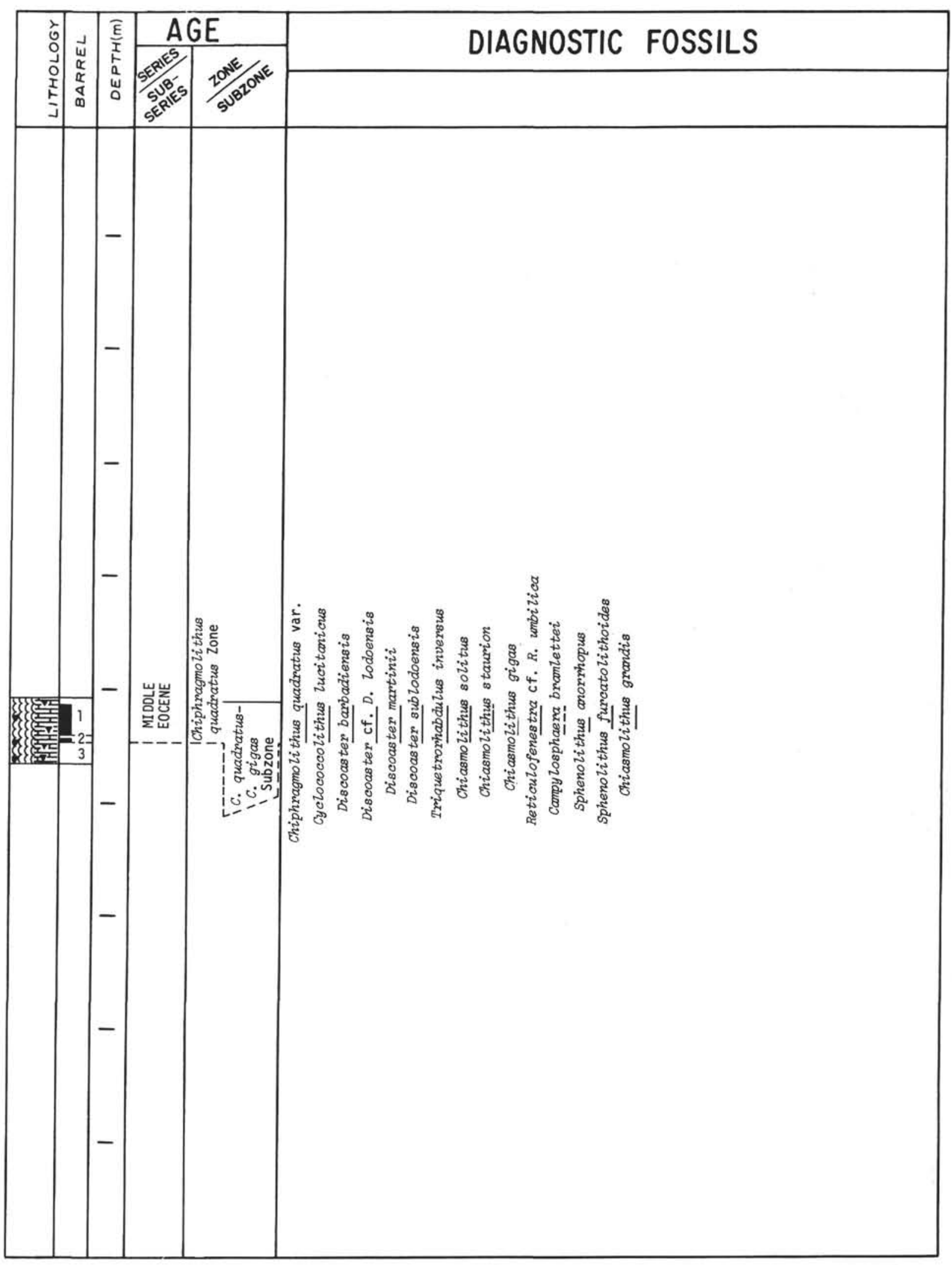

Figure 27. Summary of Cores and Diagnostic Fossils from Hole 42.1. 



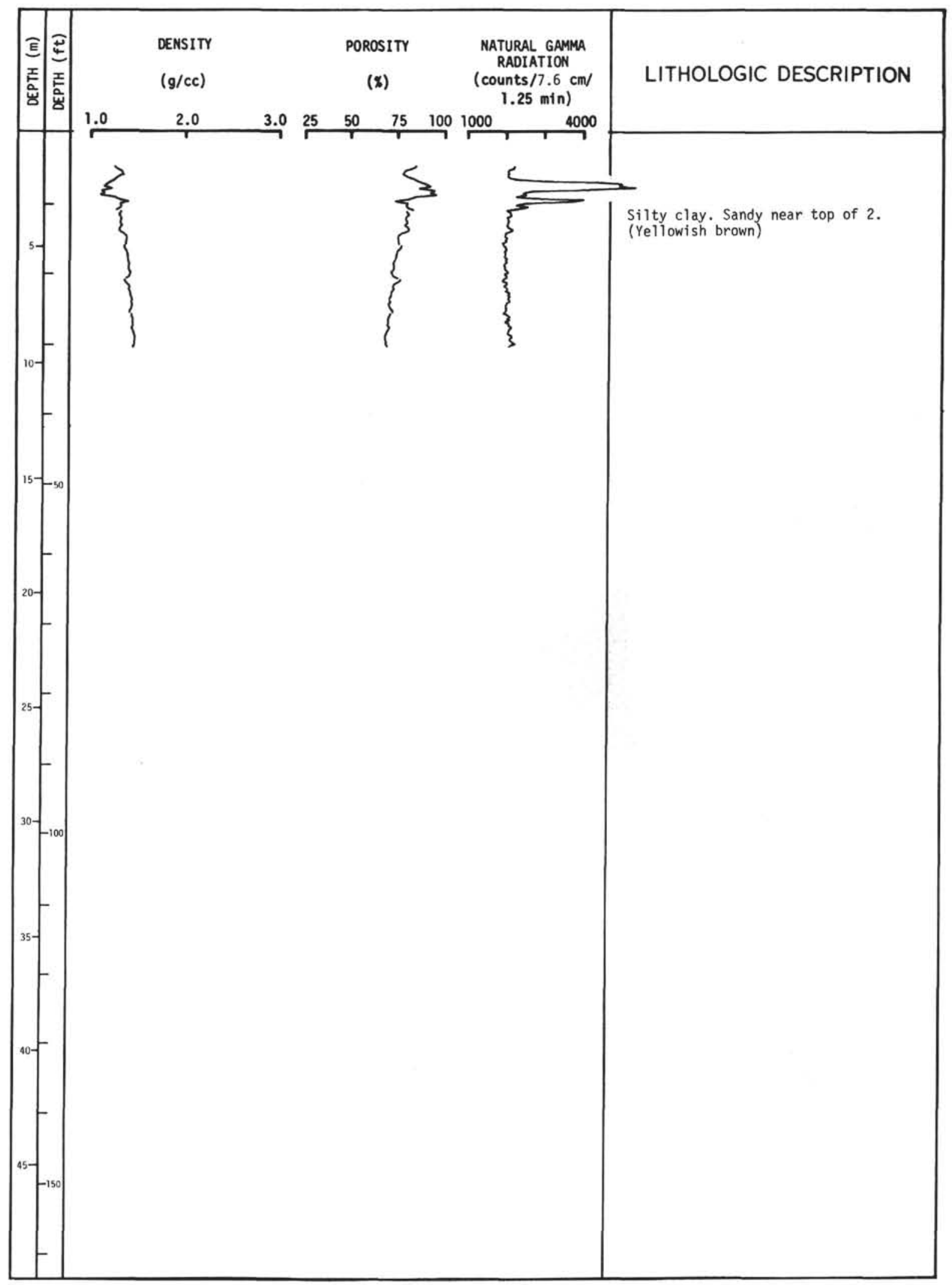

Figure 27. Summary of Physical Properties and Lithology of Hole 43. 


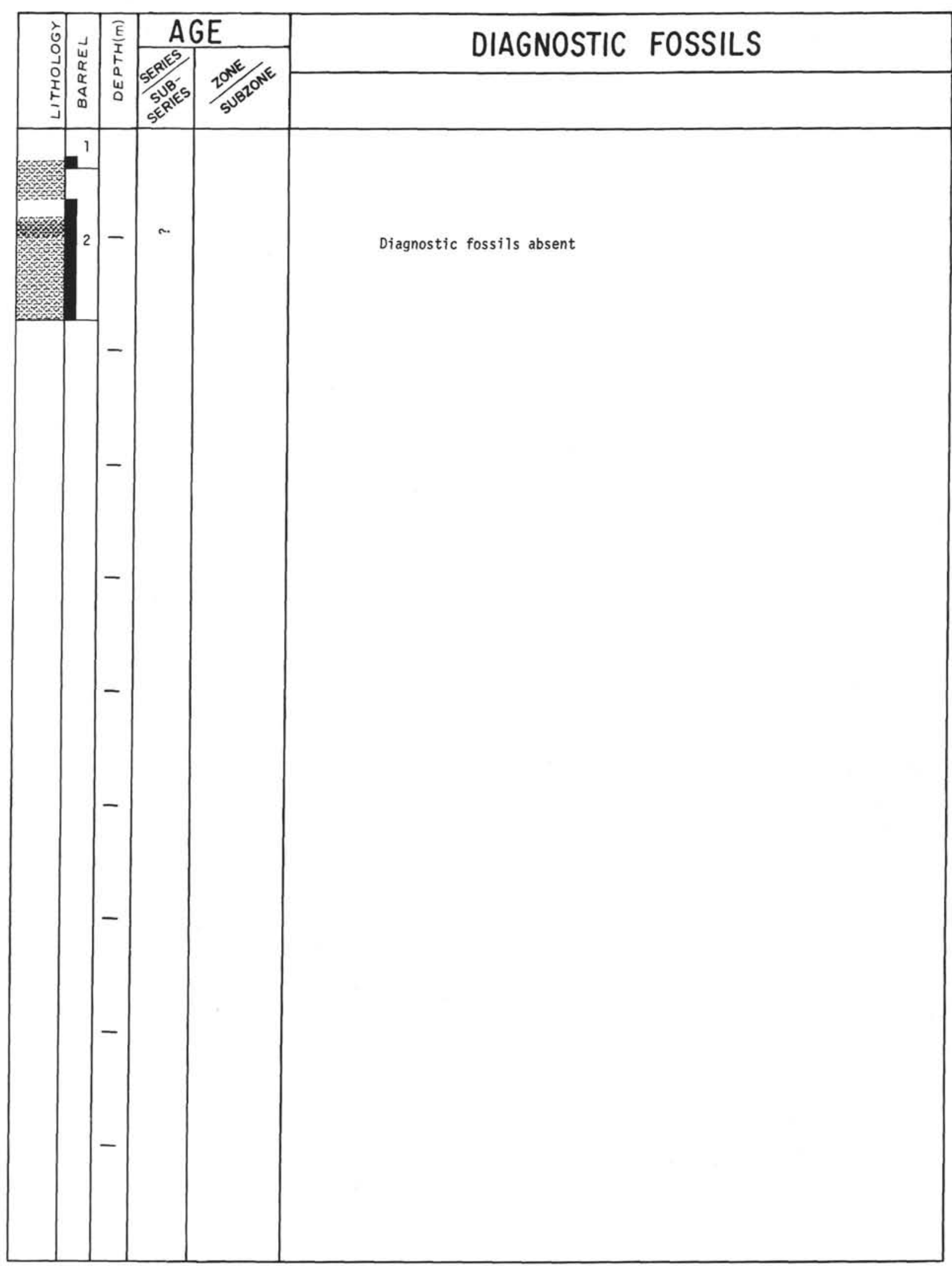

Figure 28. Summary of Cores and Diagnostic Fossils from Hole 43. 